\title{
Biocatalytic $N$-Acylation of Amines in Water Using Acyltransferase from Mycobacterium smegmatis
}

\author{
Martina Letizia Contente ${ }^{[a]}$, Andrea Pinto $^{[b]}$, Francesco Molinari*[b], Francesca \\ Paradisi*[a]
}

a School of Chemistry, University of Nottingham, University Park, Nottingham, NG7 2RD, United Kingdom Phone: +44(0)115 74 86267; e-mail: francesca.paradisi@nottingham.ac.uk

b Department of Food, Environmental and Nutritional Science, DeFENS, University of Milan, via Mangiagalli 25, Milan, Italy

Phone: (+39)-0250319148; e-mail: francesco.molinari@unimi.it

Received: ((will be filled in by the editorial staff))

Supporting information for this article is available on the WWW under http://dx.doi.org/10.1002/adsc.201\#\#\#\#\#\#.((Please delete if not appropriate))

\begin{abstract}
A straightforward one-step biocatalyzed synthesis of different $N$-acyl amides in water was accomplished using the versatile and chemoselective acyltransferase from Mycobacterium smegmatis (MsAcT). Acetylation of primary arylalkyl amines was achieved with a range of acetyl donors in biphasic systems within 1 hour and at room temperature. Vinyl acetate was the best donor which could be employed in the $N$-acetylation of a large range of primary amines in excellent yields (85-99\%) after just 20 minutes. Other acyl donors (including formyl-, propionyl-, and butyryl- donors) were also efficiently employed in the biocatalytic $N$-acylation. Finally, the biocatalyst was tested in transamidation reactions using acetamide as acetyl donor in aqueous medium, reaching yields of $60-70 \%$. This work expands the toolbox of preparative methods for the formation of $N$-acyl amides, describing a biocatalytic approach easy to accomplish under mild conditions in water.
\end{abstract}

Keywords: Amide synthesis; Biocatalysis; Transamidation; Acyltransferase; Mycobacterium smegmatis

Amide bond formation is among the most important reactions in organic chemistry due to the widespread occurrence of amides in biologically active compounds. ${ }^{[1,2]}$ In vivo, peptide bonds are created predominantly during protein biosynthesis in the ribosomes ${ }^{[3]}$, whereas $N$-acylation mediated by acetylCoA-dependent $N$-acyltransferases is a key step in the detoxification of arylamine xenobiotics. ${ }^{[4]}$

Synthetically, amide formation is a traditional reaction and can be carried out using different strategies: direct reaction between an amine and an acid mediated by coupling reagents (e.g.,

[a] Dr. M. L. Contente and Prof. F. Paradisi

School of Chemistry

University of Nottingham

University Park, Nottingham, NG7 2RD, UK

Tel: +441157486267

[b] Dr. A. Pinto and Prof. F. Molinari

DeFENS - Dept. of Food, Environmental and Nutritional Sciences

Università degli Studi di Milano

Via Celoria, 2, 20133 Milano, IT

E-mail: francesca.paradisi@nottingham.ac.uk

francesco.molinari@unimi.it

Supporting information for this article is given via a link at the end of the document. carbodiimides), reaction of an amine with an easily available acid derivative (e.g., an ester) or with acylating agents (e.g., acyl halides and symmetrical or mixed anhydrides), or from alcohols or aldehydes along with a stoichiometric oxidant. ${ }^{[5]}$ However, available methodologies tend to be inefficient and "amide formation avoiding poor atom economy" was put as one of the top challenges for organic chemists in the last decade. ${ }^{[0]}$ As an example, the preparation of $1 \mathrm{~kg}$ of the anti-HIV agent Fuzeon (36 aminoacids) requires $45 \mathrm{~kg}$ of raw material, excluding the solvents used in the synthesis and purification step. ${ }^{[7]}$ Furthermore, commonly employed harsh reaction conditions, and the lack of selectivity in the presence of additional functional groups, eliminates most biomolecules from the range of target substrates. Enzymatic strategies for amide bond formation have been achieved with ATP-dependent enzymes (generating acylphosphate intermediates), while transacylation reactions require proteases and carboxylesterases as biocatalysts. ${ }^{[8]}$ Hydrolases such as lipases form an acyl-enzyme intermediate, which can yield $N$-acyl amides through reaction with suitable amines, but, in aqueous environment, the hydrolysis of the acyl-enzyme is strongly competing, limiting these approach to organic environments. ${ }^{[9]}$ Amide synthesis in water has been reported 
using penicillin acylase predominantly applied to the production of $\beta$-lactam antibiotics; ${ }^{[10]}$ kinetic control of the synthesis is achieved through an excess of an activated donor to saturate the active site. Nevertheless, hydrolysis of the product is often a deleterious side-reaction, requiring critical and careful optimization on preparative scale to maximize yields. $^{[11]}$

A $C$-acyltransferase from Pseudomonas protegens was recently described for its promiscuous $N$-acetylation activity. ${ }^{[12]}$ While good anilide yields were achieved, reaction times between 18 and 24 hours were required. In addition, the enzyme exhibited a narrow substrate scope working only with anilines and acetyl donors.

Acetyltransferase from Mycobacterium smegmatis (MsAcT) catalyzes the formation of acetyl esters in water. ${ }^{[13]}$ Unlike many acyltransferases, it is not cofactor dependent. Its characteristic hydrophobic tunnel leading to the active site disfavors the ingress of water, thus promoting ester formation over hydrolysis. ${ }^{[13 \mathrm{~b}-\mathrm{d}]}$ Over prolonged times, the hydrolysis of the product (acetyl ester) is however observed. MsAcT, displays a secondary activity in the acylation of some primary amines using methyl methoxyacetate as acyl donor; ${ }^{[14]}$ this reaction was exploited in combination with a transaminase to shift the equilibrium in a one-pot biocatalytic cascade for the formation of amides from aldehydes or ketones.

In this work, we demonstrate that MsAcT has in fact a very broad substrate scope and can be used for the preparation of $N$-acetyl derivatives in water starting from different primary amines and using a variety of acyl donors (e.g., ethyl and vinyl esters).

Firstly, the preparation of $N$-cinnamylacetamide (2a) from $(E)$-cinnamylamine [(E)-3-phenylprop-2-en-1amine] (1a) was optimized using the inexpensive ethyl acetate as acetyl donor. Different parameters $(\mathrm{pH}$, substrate, temperature and enzyme concentration) were optimized, while keeping the amount of ethyl acetate fixed at 20 eq.; maximum conversion was used as response variable (Table 1, Supporting information).

Under optimal conditions (amine $50 \mathrm{mM}, 25^{\circ} \mathrm{C}$, enzyme $1 \mathrm{mg} / \mathrm{mL}$, phosphate buffer $100 \mathrm{mM}, \mathrm{pH} 8.0$ ), maximum yields of $53-56 \%$ were observed within 20 minutes; after prolonged times $(2 \mathrm{~h})$, in all cases, the reaction went under thermodynamic control with partial hydrolysis of the product $\mathbf{2 a}$.

Gedey et al. converted amines with CAL-B and proposed that the leaving group of the acyl donor may remain in the proximity of the active site influencing the transesterification reaction. ${ }^{[15]}$ Therefore, a screening of different acetyl donors was carried out; unactivated esters (isopropyl acetate, isoamyl acetate) and activated esters ( $p$-nitro phenyl acetate, vinyl acetate, isopropenyl acetate) were tested. 20 equivalents of acetyl donors were used (Table 1) to push the equilibrium toward the desired products. The reactions were performed under the optimized conditions described above (entry 1, Table 1 , Supporting information).
Table 1. $N$-Acetylation of $(E)$-cinnamylamine $(50 \mathrm{mM})$ catalyzed by MsAcT $(1 \mathrm{mg} / \mathrm{mL})$ in phosphate buffer $(100 \mathrm{mM}$, pH 8.0$)$ with different acetyl donors at $25^{\circ} \mathrm{C}$.

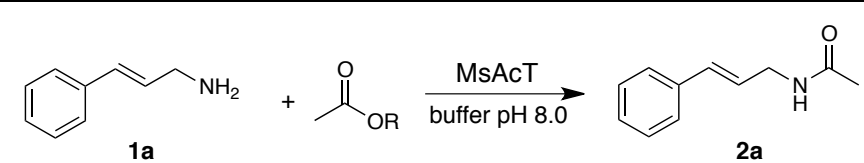

\begin{tabular}{cccc}
\hline Entry & $\mathrm{R}^{[\mathrm{a}]}$ & $\begin{array}{c}\text { Conv. } \\
(\%)\end{array}$ & $\begin{array}{c}\text { Time }^{[\mathrm{b}]} \\
(\mathrm{min})\end{array}$ \\
\hline 1 & ethyl & 53 & 20 \\
2 & isopropyl & 62 & 30 \\
3 & isoamyl & 31 & 30 \\
4 & p-nitro phenyl & 48 & 60 \\
5 & vinyl & 92 & 20 \\
6 & isopropenyl & 82 & 30 \\
\hline
\end{tabular}

[a] Acetyl donor 20 eq [b] Determined by HPLC. [c] Time corresponding to maximum conversion. No background reactions were observed under these reaction conditions.

The highest conversion (92\%) was observed with vinyl acetate (entry 5, Table 1), after 20 minutes. No reaction was observed without enzyme under the selected reaction conditions after prolonged times. The same reaction performed on preparative scale (50 $\mathrm{mL}$ ) gave $87 \%$ isolated yield of $\mathbf{2 a}$.

To further establish the synthetic applicability of the $N$-acetylation catalyzed by MsAcT, its substrate scope was investigated with different primary arylalkyl amines; the reaction was carried out using ethyl acetate and vinyl acetate as donors (Table 2).

Table 2. $N$-Acetylation of arylalkyl amines $(50 \mathrm{mM})$ catalyzed by MsAcT $(1 \mathrm{mg} / \mathrm{mL})$ in phosphate buffer $(100 \mathrm{mM}, \mathrm{pH} 8.0)$ with different acetyl donors $(20$ eq. $)$ at $25^{\circ} \mathrm{C}$.

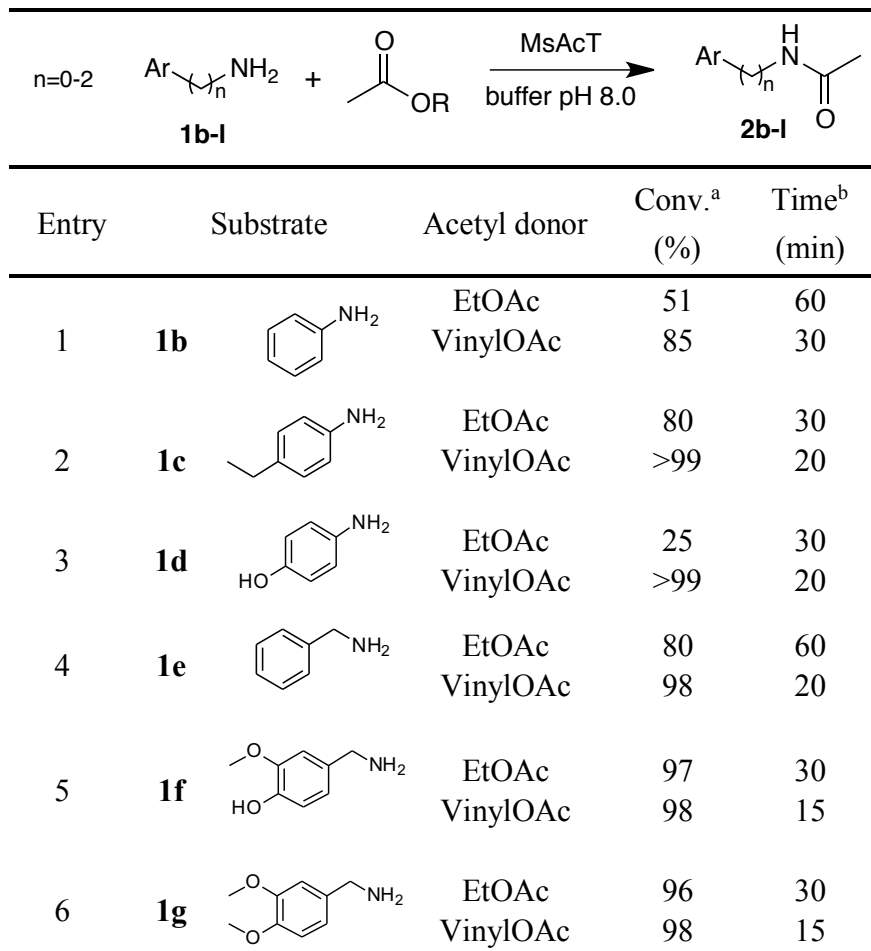




\begin{tabular}{|c|c|c|c|c|}
\hline 7 & $1 \mathrm{~h}$ & $\begin{array}{c}\text { EtOAc } \\
\text { VinylOAc }\end{array}$ & $\begin{array}{l}86 \\
98\end{array}$ & $\begin{array}{l}30 \\
20\end{array}$ \\
\hline 8 & $\mathbf{1 i}$ & $\begin{array}{c}\text { EtOAc } \\
\text { VinylOAc }\end{array}$ & $\begin{array}{c}98 \\
>99\end{array}$ & $\begin{array}{l}30 \\
15\end{array}$ \\
\hline 9 & $1 \mathrm{j}$ & $\begin{array}{c}\text { EtOAc } \\
\text { VinylOAc }\end{array}$ & $\begin{array}{c}98 \\
>99\end{array}$ & $\begin{array}{l}30 \\
15\end{array}$ \\
\hline 10 & $1 \mathrm{k}$ & $\begin{array}{c}\text { EtOAc } \\
\text { VinylOAc }\end{array}$ & $\begin{array}{c}90 \\
>99\end{array}$ & $\begin{array}{l}60 \\
20\end{array}$ \\
\hline 11 & 11 & $\begin{array}{c}\text { EtOAc } \\
\text { VinylOAc }\end{array}$ & $\begin{array}{l}51 \\
85\end{array}$ & $\begin{array}{l}30 \\
20\end{array}$ \\
\hline
\end{tabular}

All the tested amines yielded $N$-acetyl amides with both acetyl donors. The use of vinyl acetate allowed for quantitative or nearly quantitative conversions $(85-99 \%)$ in all cases; notably, high yields were obtained also with unactivated EtOAc with most of the investigated amines resulting in a very efficient and affordable process.

While MsAcT has been described as an $O$-acyl transferase, $\mathrm{N}$-acetylation of para-aminophenol and vanillylamine (entries 3, 5, Table 2) occurred completely chemoselectively, and no traces of $O$ acetylation were detected, affording paracetamol and $N$-acetyl vanillylamine with excellent yields and without any further purification step. The selective enzymatic acylation of amines in the presence of other functional groups is an efficient alternative to specific chemical reactions, such as the use of thioesters and Cu-catalysis. ${ }^{[16]}$ Both $(S)$ and $(R) \beta$ methylphenylethylamine (entry 10 , Table 2 ) were suitable substrates for MsAcT. The enzyme equally converted both enantiomers and did not show any stereopreference for this particular molecule.

We further investigated the enzyme tolerance for the acyl substrate with two model amines; $(E)$ cinnamylamine (1a) and 2-phenylethylamine (1h), and different esters with linear or branched acyl chain as donors (Table 3).

Table 3. $N$-Acylation of (E)-cinnamylamine 1a and 2phenylethylamine $\mathbf{1 h}$ catalyzed by MsAcT $(1 \mathrm{mg} / \mathrm{mL})$ in phosphate buffer $(100 \mathrm{mM}, \mathrm{pH} 8.0)$ with different acyl donors (20 eq.) at $25^{\circ} \mathrm{C}$. Initial concentration of amines was $50 \mathrm{mM}$.

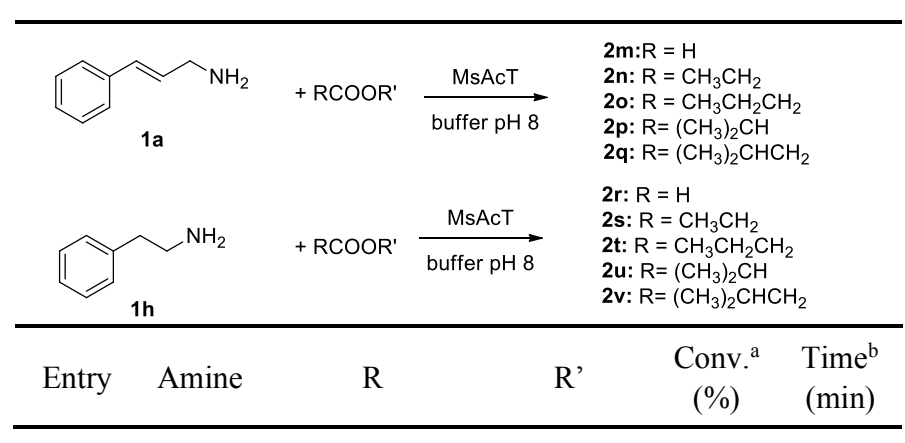

\begin{tabular}{cccccc}
\hline 1 & $\mathbf{1 a}$ & $\mathrm{H}$ & $\mathrm{CH}_{2} \mathrm{CH}_{3}$ & 60 & 60 \\
2 & $\mathbf{1 a}$ & $\mathrm{CH}_{3} \mathrm{CH}_{2}$ & $\mathrm{CH}_{2} \mathrm{CH}_{3}$ & 15 & 30 \\
3 & $\mathbf{1 a}$ & $\mathrm{CH}_{3} \mathrm{CH}_{2}$ & $\mathrm{CH}_{2}=\mathrm{CH}_{2}$ & 90 & 30 \\
4 & $\mathbf{1 a}$ & $\mathrm{CH}_{3} \mathrm{CH}_{2} \mathrm{CH}_{2}$ & $\mathrm{CH}_{2} \mathrm{CH}_{3}$ & 11 & 60 \\
5 & $\mathbf{1 a}$ & $\mathrm{CH}_{3} \mathrm{CH}_{2} \mathrm{CH}_{2}$ & $\mathrm{CH}_{2}=\mathrm{CH}_{2}$ & 56 & 30 \\
6 & $\mathbf{1 a}$ & $\left(\mathrm{CH}_{3}\right)_{2} \mathrm{CH}$ & $\mathrm{CH}_{2} \mathrm{CH}_{3}$ & 15 & 60 \\
7 & $\mathbf{1 a}$ & $\left(\mathrm{CH}_{3}\right)_{2} \mathrm{CHCH}$ & $\mathrm{CH}_{2} \mathrm{CH}_{3}$ & 25 & 60 \\
8 & $\mathbf{1 h}$ & $\mathrm{H}$ & $\mathrm{CH}_{2} \mathrm{CH}_{3}$ & 66 & 30 \\
9 & $\mathbf{1 h}$ & $\mathrm{CH}_{3} \mathrm{CH}_{2}$ & $\mathrm{CH}_{2} \mathrm{CH}_{3}$ & 45 & 60 \\
10 & $\mathbf{1 h}$ & $\mathrm{CH}_{3} \mathrm{CH}_{2}$ & $\mathrm{CH}_{2}=\mathrm{CH}_{2}$ & 97 & 30 \\
11 & $\mathbf{1 h}$ & $\mathrm{CH}_{3} \mathrm{CH}_{2} \mathrm{CH}_{2}$ & $\mathrm{CH}_{2} \mathrm{CH}_{3}$ & 38 & 60 \\
12 & $\mathbf{1 h}$ & $\mathrm{CH}_{3} \mathrm{CH}_{2} \mathrm{CH}_{2}$ & $\mathrm{CH}_{2}=\mathrm{CH}_{2}$ & 74 & 30 \\
13 & $\mathbf{1 h}$ & $\left(\mathrm{CH}_{3}\right)_{2} \mathrm{CH}_{2}$ & $\mathrm{CH}_{2} \mathrm{CH}_{3}$ & 36 & 60 \\
14 & $\mathbf{1 h}$ & $\left(\mathrm{CH}_{3}\right)_{2} \mathrm{CHCH}_{2}$ & $\mathrm{CH}_{2} \mathrm{CH}_{3}$ & 52 & 60 \\
\hline
\end{tabular}

[a] Determined by HPLC. [b] Time corresponding to maximum conversion

$N$-Formylation occurred with high rates and satisfactory conversions were observed (60\% entry 1 , and $66 \%$ entry 8 , Table 3 ); the same reaction on 50 $\mathrm{mL}$ scale gave $55 \% \mathbf{2 m}$ (isolated yield). Biopreparation of $N$-formyl amides with such rates and yields in water had not been previously reported in the literature. The most consolidated chemical methods for the preparation of these compounds rely on formylation of amines using formylating agents (e.g., acetic formic anhydride, formic acid, cyanide, $N, N$-dimethylformamide, formylfluoride).$^{[17]}$ However, these methodologies are characterized by unsustainable conditions, expensive metal/organocatalysts, and tedious procedures ${ }^{[18]} \mathrm{A}$ few examples of enzyme-mediate $\mathrm{N}$-formylation are reported involving predominantly commercial lipases (e.g., CAL-B) in an anhydrous organic environment. ${ }^{[9]}$ Aqueous enzyme-cascades or chemo-enzymatic syntheses are described exclusively for the hydrolysis of the $N$-formyl group in the deracemization of DLaminoacids. ${ }^{[20]}$ Good yields were also observed for the formation of $N$-propionyl amide $(90 \%$, entry 2 , Table 3) when vinylpropionate was used as acyl donor, whereas upon increasing the acyl chain length ( $N$-butyryl amide) only a maximum yield of $56 \%$ was achieved.

Finally, an even more challenging reaction, a biocatalytic transamidation in a homogeneous aqueous system, was explored. This reaction is often troublesome, amides are highly stable and poorly reactive, and transamidation is generally characterized by unfavourable kinetic and thermodynamic considerations. While formally transamidation is not dissimilar from the more common transesterifications, chemical strategies are scarce and usually require drastic reaction conditions making such reaction quite an atypical synthetic methodology. ${ }^{[21]}$ Recent examples of transamidation have been reported, involving both heterogeneous and homogeneous catalysis. ${ }^{[22]}$ However, environmental and practical drawbacks are nearly always reported such as the use of expensive and waste-generating reagents (e.g., hazardous acids or basis as transamidation catalysts), high temperatures or long reaction times, and the need for sealed reaction vessels to achieve water and oxygen-free conditions. 
Here, (E)-cinnamylamine (1a) and 2phenylethylamine (1h) were exploited as model substrates with 20 eq. acetamide as donor (Table 2, Supporting information for further details). The maximum molar conversion observed was between $60 \%$ and $70 \%$ with rapid reaction times $(1 \mathrm{~h} / 30 \mathrm{~min}$, respectively). The reaction was once again performed in water, validating the applicability of the method (Table 4). Transamidation of $(E)$-cinnamylamine (1a) on preparative scale $(50 \mathrm{~mL})$ gave $57 \%$ isolated yield of $2 \mathrm{a}$.

Table 4. $N$-Acetylation of $(E)$-cinnamylamine $\mathbf{1 a}$ and 2phenylethyalmine $\mathbf{1 h}$ catalyzed by MsAcT $(1 \mathrm{mg} / \mathrm{mL})$ by transamidation with acetamide (20 eq.) in phosphate buffer (100 $\mathrm{mM}, \mathrm{pH} \mathrm{8.0)}$ at $25{ }^{\circ} \mathrm{C}$. Initial concentration of amines was 50 $\mathrm{mM}$.

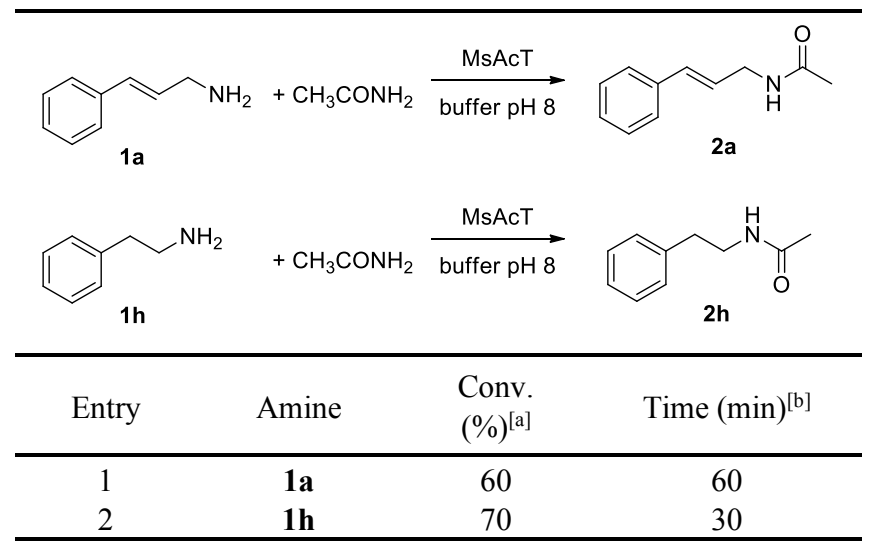

[a] Determined by HPLC. [b] Time corresponding to maximum conversion

Despite the known solubility problems of many organic substrates in water, the possibility to synthesize amides in aqueous media seems noteworthy. This study shows that biocatalytic $N$ acylation of different amines can be realized in water with good-to-excellent yields using the stable and easy-to-produce acyltransferase from Mycobacterium smegmatis (MsAcT); the applicability and chemoselectivity of the proposed strategy was successfully applied for the preparation of different amides in excellent yields. Notably, also $N$-formyl amides were produced in this simple and straightforward one-step technique, which does not require any particular formylating agent and/or tedious subsequent purification. Finally, we have demonstrated that this enzyme can also efficiently catalyze challenging transamidation reactions between primary amines and acetamide in aqueous medium without the need for a dry reaction environment or oxygen-free conditions, demonstrating an alternative, useful, and applicable method for the preparation of amides. This strategy for amide bond formation sheds light on the importance of developing catalytic methods addressing what is recognized as an unmet synthetic need.

\section{Experimental Section}

\section{General}

NMR spectra were recorded on a Varian Gemini 300 $\mathrm{MHz}$ spectrometer using the residual signal of the deuterated solvent as internal standard. ${ }^{1} \mathrm{H}$ chemical shifts $(\delta)$ are expressed in ppm, and coupling constants $(J)$ in hertz $(\mathrm{Hz})$. Merck Silica gel 60 F254 plates were used for analytical TLC; flash column chromatography was performed on Merck Silica gel (200-400 mesh).

\section{Chemicals}

All reagents and solvents were obtained from commercial suppliers and were used without further purification.

\section{Cloning, Overexpression and Purification of MsAcT}

A synthetic gene encoding for MsAcT (GenBank accession: ABK70783) from Mycobacterium smegmatis str. MC2 155 was purchased from BaseClear. The gene was cloned into vector pET26b (Novagen) with C-terminal his-tag. Restriction sites for NdeI and BamHI were inserted by PCR using 5'CCGACATATGGCTAAACGTATTCTGTGC-3' as forward and 5'CTTGGATCCAGCAGAGAACGAACTTGT-3' as reverse primer. The PCR product was then cloned into pET26b expression vector and the resulting pET26b-MsAcT transformed into chemically competent $E$. coli BL21 star (DE3) for heterologous expression. Culture of E. coli BL21 star (DE3) pETbMsAcT $(20 \mathrm{~mL})$ was grown overnight at $37^{\circ} \mathrm{C}$ in LB medium supplemented with $25 \mu \mathrm{g} / \mathrm{mL}$ kanamycin. $200 \mathrm{~mL}$ of cultivation medium (Terrific Broth: $12 \mathrm{~g} / \mathrm{L}$ bacto-tryptone, $24 \mathrm{~g} / \mathrm{L}$ yeast extract, $4 \mathrm{~g} / \mathrm{L}$ glycerol, $2.3 \mathrm{~g} / \mathrm{L} \quad \mathrm{KH}_{2} \mathrm{PO}_{4}, \quad 9.4 \mathrm{~g} / \mathrm{L} \quad \mathrm{K}_{2} \mathrm{HPO}_{4}, \quad 25 \quad \mu \mathrm{g} / \mathrm{mL}$ kanamycin, $\mathrm{pH}$ 7.2) were inoculated with the previous described seed culture to an initial $\mathrm{OD}_{600 \mathrm{~nm}}$ of 0.1 . Cultivation was carried out at $37^{\circ} \mathrm{C}, 150 \mathrm{rpm}$. Cells were grown until $\mathrm{OD}_{600 \mathrm{~nm}}$ reached the value of 0.5 . The expression of MsAcT was induced by the addition of isopropyl- $\beta$-d-thiogalactopyranoside (IPTG) to a final concentration of $0.1 \mathrm{mM}$. The culture was further incubated for $16 \mathrm{~h}$ at $25^{\circ} \mathrm{C}$. Cells were then harvested by centrifugation ( $20 \mathrm{~min}, 4500$ $\mathrm{rpm}, 4{ }^{\circ} \mathrm{C}$ ), washed once with $20 \mathrm{mM}$ phosphate buffer $\mathrm{pH} 8.0$ and stored at $-20^{\circ} \mathrm{C}$.

$2 \mathrm{~g}$ of pellet were resuspended in $10 \mathrm{~mL}$ loading buffer $(100 \mathrm{mM}$ phosphate buffer $\mathrm{pH} 8.0,6 \mathrm{mM}$ imidazole, $100 \mathrm{mM} \mathrm{NaCl})$ and sonicated $(5$ cycles of 2 min each, in ice, with 1 min interval). Cell debris were harvested by centrifugation (45 min, $15000 \mathrm{rpm}$, $\left.4{ }^{\circ} \mathrm{C}\right)$. The enzyme was purified by affinity chromatography with HIS-Select ${ }^{\circledR}$ Nickel Affinity Gel. Briefly, the column was equilibrated with loading buffer and the crude extract loaded; column was then washed with loading buffer; finally, the adsorbed enzyme was eluted with elution buffer 
(phosphate buffer $100 \mathrm{mM}$ pH 8.0, $250 \mathrm{mM}$ imidazole, $100 \mathrm{mM} \mathrm{NaCl}$ ).

Crude extract, pellet and pure protein were analyzed by SDS-PAGE (See Supporting information, Fig. S1). The fractions showing the presence of a band of the expected size $(25.6 \mathrm{kDa})$ were pooled, dialyzed against $100 \mathrm{mM}$ phosphate buffer $\mathrm{pH} 8.0$ and stored at $4{ }^{\circ} \mathrm{C}$. Typically, starting from $2 \mathrm{~g}$ of wet cell paste, it was possible to obtain $130 \mathrm{mg}$ of pure protein $(8.5$ $\mathrm{mg} / \mathrm{mL})$.

\section{MsAcT activity assay}

Activity measurements were performed spectrophotometrically at $400 \mathrm{~nm}$ by determining the formation of $p$-nitrophenol at $25{ }^{\circ} \mathrm{C}$ in a halfmicrocuvette (total volume $1 \mathrm{~mL}$ ) for $2 \mathrm{~min}$. One unit (U) of activity is defined as the amount of enzyme which catalyzes the consumption of $1 \mu \mathrm{mol}$ of $p$ nitrophenylacetate per minute under reference conditions, namely $0.1 \mathrm{mg} / \mathrm{mL} p$-nitrophenylacetate, $0.1 \% \mathrm{v} / \mathrm{v} \mathrm{EtOH}$, correct amount of MsAcT in 100 $\mathrm{mM}$ phosphate buffer, $\mathrm{pH}$ 8.0. Specific activity was $800 \mathrm{U} / \mathrm{mg}$.

\section{Small scale batch reactions}

Batch reactions using MsAcT were performed in 10 $\mathrm{mL}$ screw cap tubes; $1 \mathrm{~mL}$ reaction mixture in 100 $\mathrm{mM}$ phosphate buffer $\mathrm{pH} 8.0$, containing $50 \mathrm{Mm}$ amine, $1 \mathrm{mg} / \mathrm{mL}$ enzyme, and 20 eq. acyl donor were left under magnetic stirring at $25^{\circ} \mathrm{C}$. $50 \mu \mathrm{L}$ aliquots were quenched with $\mathrm{NaOH} 1 \mathrm{M}$ or $\mathrm{NaHCO} 35 \%$ (in the case of vanillyamine and $p$-aminophenol) at different reaction times $(10 \mathrm{~min}, 20 \mathrm{~min}, 30 \mathrm{~min}, 1 \mathrm{~h}$, $2 \mathrm{~h}, 4 \mathrm{~h}$ ) and extracted with $100 \mu \mathrm{L}$ of EtOAc for TLC $\left(\mathrm{CH}_{2} \mathrm{Cl}_{2} / \mathrm{MeOH}\right.$ 9:1 $+0.1 \%$ TEA $)$. Samples, after evaporation, were resuspended in the mobile phase for HPLC analysis.

\section{HPLC Analysis}

See supporting information.

\section{Preparative scale batch reactions}

Preparative scale reactions using MsAcT were performed in $100 \mathrm{~mL}$ round bottom flasks; $50 \mathrm{~mL}$ reaction mixtures $(100 \mathrm{mM}$ phosphate buffer $\mathrm{pH} 8.0$, $50 \mathrm{mM}$ amine, $1 \mathrm{mg} / \mathrm{mL}$ enzyme, and 20 eq. acyl donor) were left under magnetic stirring at $25^{\circ} \mathrm{C}$. The reaction mixture was monitored by TLC $\left(\mathrm{CH}_{2} \mathrm{Cl}_{2} / \mathrm{MeOH}\right.$ 9:1 + 0.1\% TEA), quenched with $\mathrm{NaOH} 1 \mathrm{M}$ when the maximum conversion was reached. After extraction (EtOAc: $3 \times 30 \mathrm{~mL}$ ), the organic phase was collected, dried over $\mathrm{Na}_{2} \mathrm{SO}_{4}$, filtrated and evaporated under reduced pressure. The crude extract was purified by silica gel column chromatography (EtOAc/n-hexane 9:1).
This project was supported by the European Union's Horizon 2020 research and innovation programme under the Marie Skłodowska-Curie grant agreement N. 792804_AROMAs-FLOW (M.L.C.). A.P. was financially supported by the "Piano di Sostegno alla Ricerca 2015/2017-Linea 2 Azione A" of the University of Milan.

\section{References}

[1] A. Greenberg, C. M. Breneman, J. F. Liebman. The amide linkage: structural significant in chemistry, biochemistry and material science Wiley-Interscience: New York, 2000.

[2] V. R. Pattabiraman, J. W. Bode. Nature, 2011, 480, 471-479.

[3] T. M. Schmeing, V. Ramakrishnan. Nature 2009, 461, 1234-1242.

[4] S. K. Walters, S. Boukouvala. Drug Metab Rev, 2008, 40, 479-510.

[5] J. E. Taylor, S. D. Bull. N-Acylation Reactions of Amines in Comprehensive Organic Synthesis: Second Edition (Eds.: P. Knochel, G. A. Molander), Elsevier, Amsterdam, 2014, pp. 427-478.

[6] D. J. C. Constable, P. J. Dunn, J. D. Hayler, G. R. Humphrey, J. L. Leazer Jr., R. J. Linderman, K. Lorenz, J. Manley, B. A. Pearlman, A. Wells, A. Zaksh, T. Y. Zhang. Green Chem. 2007, 9, 411-420.

[7] V. Marx. Chem. Eng. News 2005, 83, 16-17.

[8] A. Goswami, S. G. Van Lanen. Mol. BioSyst., 2015, 11, 338-353.

[9] a) F. van Rantwijk, R. A. Sheldon, Tetrahedron 2004, 60, 501-519. b) V. Gotor-Fernandez, E. Busto, V. Gotor Adv. Synth. Catal. 2006, 348, 797-812. c) B. M. Dorr, D. E. Fuerst. Curr. Opin. Chem. Biol. 2018, 43, 127-133.

[10] A. Bruggink, E. C. Roos, E. de Vroom. Org. Process. Res. Dev. 1998, 2, 128-133.

[11] a) R. C. Giordano, M. P. Ribeiro, R. L. Giordano. Biotechnol. Adv. 2006, 24, 27-41. b) D. Romano, R. Gandolfi, S. Guglielmetti, F. Molinari. Food Chem. 2011, 124, 1096-1098.

[12] A. Zadło-Dobrowolska, N. G. Schmidt, W. Kroutil. Chem. Commun. 2018, 54, 3387-3390.

[13] a) I. Mathews, M. Soltis, M. Saldajeno, G. Ganshaw, R. Sala, W. Weyler, M. A. Cervin, G. Whited, R. Bott Biochemistry 2007, 46, 8969-8979 b) N. de Leeuw, G. Torrelo, C. Bisterfeld, V. Resch, L. Mestrom, E. Straulino, L. van der Weel, U. Hanefeld, Adv. Synth. Catal. 2018, 360, 242-249. c) A. Drozdz, U. Hanefeld, K. Szymańska, A. Jarzebski, A. Chrobok, Catal. Commun. 2016, 81, 37-40. d) K. Szymańska, K. Odrozek, A. Zniszczol, G. Torrelo, V. Resch, U. Hanefeld, A. B. Jarzebski, Catal. Sci. Technol. 2016, 6, 4882-4888.

[14] H. Land, P. Hendil-Forssell, M. Martinelle, P. Berglund. Catal. Sci. Technol. 2016, 6, 2897-2900.

[15] S. Gedey, A. Liljeblad, F. Fulop, L. T. Kanerva. Tetrahedron: Asymmetry 1999, 10, 2573-2581.

[16] S. M. Mali, R. D. Bhaisare, H. N. Gopi. J. Org. Chem., 2013, 78, 5550-5555.

\section{Acknowledgements}


[17] a) P. Strazzolini, A. G. Giumanini and S. Cauci. Tetrahedron, 1990, 46, 1081-1118 b) M. Waki, J. Meinhofer. J. Org. Chem., 1977, 42, 2019-2020 c) K. Bao, W. Zhang, X. Bu, Z. Song, L. Zhang, M. Cheng. Chem. Commun., 2008, 5429-5431 d) S. W. Djuric. J. Org. Chem., 1984, 49, 1311-1312 e) G. A. Olah, S. J. Kuhn. J. Am. Chem. Soc., 1960, 82, 2380-2382.

[18] C. J. Gerack, L. McElwee-White. Molecules, 2014, 19, 7689-7713.

[19] R. Patre, S. Mal, P. R. Nilkanth, S. K. Ghorai, S. H. Deshpande, M. El Qacemi, T. Smejkal, S. Pala, B. N. Manjunath. Chem. Commun., 2017, 53, 2382-2385.

[20] a) P. Soriano-Maldonado, M. J. Rodríguez-Alonso, C. Hernández-Cervantes, I. Rodríguez-García, J. M. Clemente-Jiménez, F. Rodríguez-Vico, S. MartínezRodríguez, F. J. Las Heras-Vázquez. Process Biochem. 2014, 49, 1281-1287 b) A. Chaplin, M. D. Levin, B. Morgan,a N. Farid, J. Li,Z . Zhu, J. McQuaid, L. W. Nicholson, C. A. Rand, M. J. Burk. Tetrahedron: Asymmetry 2004, 15, 2793-2796.

[21] R. M Lanigan, T. D. Sheppard. Eur. J. Org. Chem. 2013, 7453-7465.

[22] a) S. E. Eldred, D. A Stone, S. H. Gellman, S. S. Stahl. J. Am. Chem. Soc. 2003, 125, 3422-3423. b) T. A. Dineen, M. A. Zajac, A. G. Myers. J. Am. Chem. Soc. 2006, 128, 16406-16409. c) C. L. Allen, B. N. Atkinson, J. M. J. Williams. Angew. Chem. Int. Ed. 2012, 51, 1383-1386. d) T. B. Nguyen, J. Sorres, M. Q. Tran, L. Ermolenko, A. Al-Mourabit. Org. Lett. 2012, 14, 3202-3205. e) M. Tamura, T. Tonomura, K. I. Shimizu, A. Satsuma. Green Chem. 2012, 14, 717-724. f) M. Zhang, S. Imm, S. Bähn, L. Neubert, H. Neumann, M. Beller. Angew. Chem., Int. Ed. 2012, 51, 3905-3909. 


\section{UPDATE}

Biocatalytic $N$-Acylation of Amines in Water Using Acyltransferase from Mycobacterium smegmatis

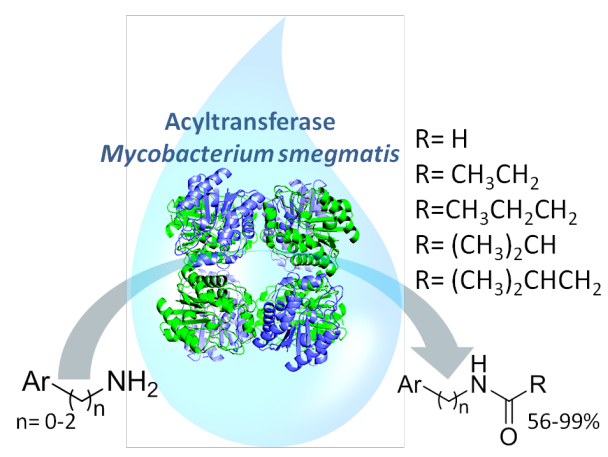

Martina Letizia Contente, Andrea Pinto, Francesco Molinari*, Francesca Paradisi*

$$
\operatorname{Ar}_{n=0-2} Y_{n} \mathrm{NH}_{2} \quad \operatorname{Ar}_{X_{n}}{ }^{\mathrm{N}} \prod_{0}^{\mathrm{R}} \mathrm{R6-99 \%}
$$

